\title{
A case for transparent net-zero carbon targets
}

Stephen M. Smith (10) ${ }^{1 凶}$

Perceived risks from carbon dioxide removal have led to calls for net zero targets to be split into separate goals for removals and emissions. A better approach is to accompany net targets with ambitious near-term action, disclose measures to achieve them and closely monitor and manage carbon sinks.

Alongside emission reduction (ER), carbon dioxide removal (CDR) is a key component of pathways to achieve net-zero emissions and the goals of the Paris Agreement ${ }^{1}$, and essential if future generations aim for net-negative emissions. Net zero is now targeted by many countries, cities and businesses ${ }^{2}$. The role of CDR in strategies is perceived to carry risks to successful mitigation, however, and separating out targets for ER and CDR has been proposed as a way to reduce these risks ${ }^{3}$. This has rapidly gained traction, being endorsed in an increasing number of policy-facing briefings ${ }^{4-6}$ and emerging as an issue for the EU's updated 2030 climate package ${ }^{7}$.

A wide range of techniques make up CDR, such as afforestation, soil carbon sequestration, enhanced weathering, biochar, bioenergy with carbon capture and storage, and direct air carbon capture and storage ${ }^{8}$. Each involves a chain of technologies and actions (e.g. tree planting, biomass harvesting, carbon capture), carried out by different agents (such as land managers, power generators and geological engineers) and using different carbon stores (biological and geological). CDR is not one single technology, nor is it separate entirely from ER; elements of these chains contribute to ER as well.

Here I argue that these complexities and connections mean target separation is not an efficient way to ensure that climate goals are achieved. I propose an alternative approach to manage risks, which applies across both ER and CDR. To support this, I summarise and critique five issues that are cited to justify target separation.

\section{Delay now, remove later}

Perhaps the primary distinguishing feature of $\mathrm{CDR}$ is that it offers the potential to reverse an overshoot of carbon budgets and hence global temperature. Actors could therefore set mitigation targets on a delayed timetable, based on the uncertain assumption that CDR can recover the climate at a later date. Even if CDR is able to reverse global average temperature, many other aspects of climate will be less reversible, if at all ${ }^{9}$.

Of the 90 modelled pathways considered $1.5^{\circ} \mathrm{C}$-consistent by the IPCC, only nine avoid overshoot. 37 include overshoot greater than $0.1{ }^{\circ} \mathrm{C}$, relying on extensive CDR to return by the end of the century ${ }^{10}$. The risk of reliance on CDR leading to higher peak temperatures and greater climate change is therefore material.

In these modelled pathways, peak temperature is only weakly linked to the level of CDR at the time of net-zero emissions. Even the timing of net-zero emissions itself is not a clear indicator of peak temperature (although this only considers cases in which mitigation is strong enough to halt

\footnotetext{
${ }^{1}$ Smith School of Enterprise and the Environment, University of Oxford, Oxford, UK. ${ }_{\text {email: stephen.smith@smithschool.ox.ac.uk }}$
} 
temperature rise before 2100). A much better indicator is the rate of net ER over the next decade (Fig. 1). This is because warming is driven primarily by cumulative emissions over time, and so delayed mitigation in the near term-when the rate of increase in cumulative emissions is high-adds strongly to peak temperature ${ }^{11}$.

Separating out the CDR component of net-zero targets is therefore a poor indicator of overshoot risk. A better approach to ensure temperature limits are not breached is to supplement netzero targets with stringent nearer-term targets.

\section{Trading responsibilities}

Some concerns over the role of CDR derive from use of the term offsetting. CDR is often referred to as offsetting emissions, however offsetting also has widely-used meaning as the use of traded carbon credits to meet a target (the credit arising from mitigation by another actor outside the target). These two concepts are sometimes conflated, or linked ambiguously ${ }^{12}$, despite being different. Traded offsets can reduce costs for actors to meet their targets and provide flexibility to go further, but face issues regarding lack of additionality, double-counting and disincentivising ambition ${ }^{13}$.

Credit for CDR activities need not be traded between actors-a nation can plant trees on its own land to meet its target, or a biomass power operator can apply carbon capture and storage to its own units. And traded offsets need not derive from CDR projects - to date most have come from ER activities, despite a recent surge in afforestation projects in some markets ${ }^{14,15}$.

Views differ on the role for CDR in offset markets. Concerns over lack of permanence, displacement of emissions and complexities of verification, mainly for biological methods, have led some to argue CDR should not be included at all ${ }^{5}$. Others argue CDR should make up an increasing share provided standards of environmental integrity are met, although leaving open the question of whether such standards can be attained in practice ${ }^{16}$. Regardless of the extent to which traded offsets come from CDR projects in future, the risks specific to trading are best managed by actors prioritising mitigation in their own sphere of influence and only accounting for credits in targets if they have high environmental integrity (or not at all) ${ }^{13}$.

\section{Emissions lock-in}

Another proposed risk to meeting targets comes if CDR suppresses ER, locking-in emitting activities. Examples given include use of direct air capture or afforestation while continuing with coal-fired power, and possible diversion of direct air capture from storage to making hydrocarbon fuels, as well as use of traded CDR credits $^{3}$.

Lock-in of emissions is clearly a far greater risk where there is no ambition, so the existence of a net-zero target goes a long way to address this. But even with such a target the concept of lock-in should not be ignored-the role of CDR in pathways to net zero is to substitute for some level of residual emissions, after all.

Possible cases of lock-in are not limited to CDR, however. Older solar photovoltaic technologies may be diverting support from newer, more efficient ones, while low-emission cars may suppress less energy- and material-intensive travel options ${ }^{17}$. Lock-in is a complex, context-specific function not only of technologies but also infrastructures, institutions and behaviours. Discerning where measures may suppress others-or indeed enhance them-requires more information than simply the total targeted CDR and ER. It requires details of the specific measures and arrangements expected to meet targets.

\section{Fail to scale}

A fourth case for target separation is that CDR techniques, generally at an early stage of development, may not reach expected levels of deployment. Linked to this, separate targets are claimed to clarify responsibilities, helping to prepare for the netnegative phase required later in the century ${ }^{5}$ and develop the different incentives beyond carbon pricing that early-stage CDR requires ${ }^{3}$.

While some elements of CDR are at an early stage, there are ER techniques at similar levels of technology readiness which are also important for achieving net zero ${ }^{18}$. Other CDR techniques are well-developed, including afforestation and soil carbon management ${ }^{19}$. All mitigation measures face some uncertainty in delivery, for reasons not only of technology readiness but also policy effectiveness and social preferences. A mitigation-wide approach to avoiding over-reliance on speculative techniques and reducing deployment failures is thus needed. This could include setting targets (net or separate) to over-achieve the desired outcome, and/or redundancy in measures to achieve the targets.

The case for incentives differentiated by technique and stage applies to ER as well. Given the range of low-carbon incentives in existence it seems that avoiding a one-size-fits-all approach is no problem for policymakers; in fact, quite the opposite. For example, the UK has a net-zero target and provides price guarantees for renewable power, grants for afforestation and renewable heat, product standards for energy-efficient appliances, and provides innovation funding for early stage technologies ${ }^{20}$.

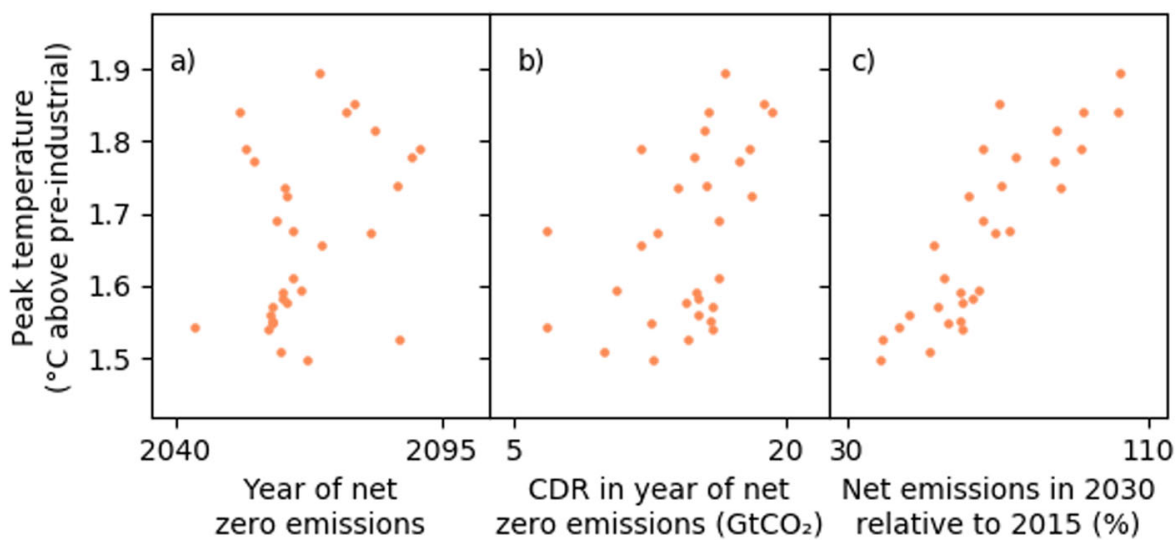

Fig. 1 Correlates of peak global temperature in ambitious mitigation scenarios. Relationship between peak temperature and (a) the timing of global netzero emissions, (b) the level of global anthropogenic carbon dioxide removal (CDR) at that time, and (c) global net greenhouse gas emissions in 2030 as a percentage of those in 2015. Data taken from model scenarios in the database of the IPCC Special Report on Global Warming of $1.5^{\circ} \mathrm{C}^{10}$, specifically those that include CDR data and reach both peak temperature and net-zero emissions before 2100. 


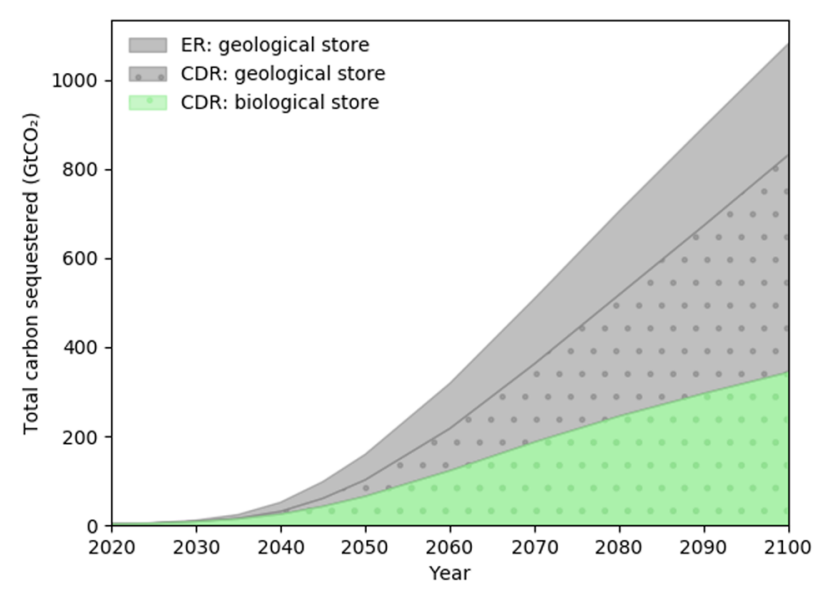

Fig. 2 Carbon storage in mitigation scenarios. Illustration of the accumulated total carbon placed into storage during 2005 to 2100 by anthropogenic activities. Carbon is stored not only from carbon dioxide removal (CDR) but also emission reduction (ER), and placed into both biological (green) and geological (grey) sinks. Taken from medians of model scenarios used in Fig. 1.

\section{Carbon comeback}

Because CDR involves carbon storage there is a risk of $\mathrm{CO}_{2}$ being re-released into the air. The greater the amount of carbon being stored, the greater the potential subsequent emissions which could undermine mitigation.

Biological and geological carbon sinks have very different timescales for storage and drivers of disturbance ${ }^{21}$. In net-zero pathways a significant amount of geological storage is also used for ER, coupled to fossil and chemical sources of $\mathrm{CO}_{2}$ (Fig. 2). Carbon in forests and soils is more susceptible to loss, and is particularly challenging to monitor and verify: it is in dynamic exchange with the air through a variety of processes both human and natural, and national targets face a critical lack of transparency and compatibility ${ }^{22}$.

While there may thus be a case for distinguishing between fossil and biological carbon in targets, aggregating biological and geological removal for the purpose of managing storage risk is an incomplete approach. The correct unit of analysis to manage this risk is the total amount of carbon in each sink, whether from ER or CDR measures.

For all these cited risks to successful mitigation, separation at the level of ER versus CDR adds complexity to targets but does not provide enough detail to effectively manage the different risks cited to justify it.

\section{A way forward}

I propose a three-point plan to accompany targets that would help actors better address the drivers of risk across both ER and CDR:

- Set targets consistent with achieving climate goals without overshoot. Importantly this will include ambitious near-term action, as this is a distinguishing feature of pathways with lower peak temperatures.

- Set out the mix of measures planned to achieve the target. Publish a clear plan detailing the ER and CDR measures to achieve the targets. This ensures accountability and means that responsibilities and policies required to deliver them can be identified. Any traded offsets used, be they from ER or CDR measures, must have high environmental integrity. The plan should be robust to potential under-delivery of measures.
- Set out the carbon storage involved, and have plans to monitor and manage it. This includes $\mathrm{CO}_{2}$ stored from ER measures, and should be differentiated by type (e.g. biological and geological). The greater the sink, the greater the need for monitoring and for plans to reduce and deal with possible leakage.

These three elements together are a more comprehensive and incisive way to ensure action meets ambition than separating targets into emissions and removals. They should be adopted by any actor claiming ambitious targets, such as net zero, which are likely to involve removal as well as ER. Dividing emissions and removals into separate targets is at best only a partial approach, and at worst a distraction from the much greater transparency needed.

Received: 12 November 2020; Accepted: 21 December 2020; Published online: 04 February 2021

\section{References}

1. IPCC. Summary for Policymakers. in Global Warming of $1.5^{\circ} \mathrm{C}$. An IPCC Special Report on the Impacts of Global Warming of $1.5^{\circ} \mathrm{C}$ Above Preindustrial Levels and Related Global Greenhouse Gas Emission Pathways, in the Context of Strengthening the Global Response to the Threat of Climate Change, Sustainable Development, and Efforts to Eradicate Poverty (World Meteorological Organization, 2018).

2. Day, T. et al. Navigating the Nuances of Net-zero Targets (NewClimate Institute \& Data-Driven EnviroLab, 2020).

3. McLaren, D. P., Tyfield, D. P., Willis, R., Szerszynski, B. \& Markusson, N. O. Beyond "net-zero": a case for separate targets for emissions reduction and negative emissions. Front. Clim. 1, https://doi.org/10.3389/fclim.2019.00004 (2019).

4. Geden, O. \& Schenuit, F. Unconventional Mitigation (Stiftung Wissenschaft und Politik, 2020). https://doi.org/10.18449/2020RP08

5. Jeffery, L., Höhne, N., Moisio, M., Day, T. \& Lawless, B. Options for supporting Carbon Dioxide Removal (NewClimate Institute, 2020).

6. Levin, K., Rich, D., Ross, K., Fransen, T. \& Elliott, C. Designing and Communicating Net-Zero Targets (World Resources Institute, 2020).

7. Simon, F. Commission under fire for including 'carbon sinks' into EU climate goals. www.euractiv.com https://www.euractiv.com/section/climateenvironment/news/commission-under-fire-for-including-carbon-sinks-intoeu-climate-goals/ (2020).

8. National Academies of Sciences, Engineering \& Medicine. Negative Emissions Technologies and Reliable Sequestration: A Research Agenda (The National Academies Press, 2019). https://doi.org/10.17226/25259.

9. Wu, P., Ridley, J., Pardaens, A., Levine, R. \& Lowe, J. The reversibility of $\mathrm{CO}_{2}$ induced climate change. Clim. Dyn. 45, 745-754 (2015).

10. Huppmann, D., Rogelj, J., Kriegler, E., Krey, V. \& Riahi, K. A new scenario resource for integrated $1.5^{\circ} \mathrm{C}$ research. Nat. Clim. Change 8, 1027-1030 (2018).

11. Allen, M. R. \& Stocker, T. F. Impact of delay in reducing carbon dioxide emissions. Nat. Clim. Change 4, 23-26 (2014).

12. Rathi, A. \& Gillespie, T. With Big Oil Declining, Carbon Removal Could Take Its Place (Bloomberg, 2020).

13. Schneider, L. \& Theuer, S. L. H. Environmental integrity of international carbon market mechanisms under the Paris Agreement. Clim. Policy 19, 386-400 (2019).

14. UNEP DTU CDM/JI Pipeline Analysis and Database. https://www. cdmpipeline.org/cdm-projects-type.htm.

15. Donofrio, S., Maguire, P., Zwick, S. \& Merry, W. State of the Voluntary Carbon Markets 202016 (Forest Trends' Ecosystem Marketplace, 2020).

16. Allen, M. et al. The Oxford Principles for Net Zero Aligned Carbon Offsetting 15 (University of Oxford, 2020).

17. Seto, K. C. et al. Carbon lock-in: types, causes, and policy implications. Annu. Rev. Environ. Resour. 41, 425-452 (2016).

18. Sha, F. et al. Energy Technology Perspectives 2020-Special Report on Clean Energy Innovation 185 (International Energy Agency, 2020).

19. Royal Society, Royal Academy of Engineering. Greenhouse Gas Removal (Royal Society, Royal Academy of Engineering, 2018).

20. Committee on Climate Change. Reducing UK Emissions: 2020 Progress Report to Parliament. https://www.theccc.org.uk/publication/reducing-uk-emissions2020-progress-report-to-parliament/ (2020).

21. Hepburn, C. et al. The technological and economic prospects for $\mathrm{CO}_{2}$ utilization and removal. Nature 575, 87-97 (2019). 
22. Grassi, G. et al. Reconciling global-model estimates and country reporting of anthropogenic forest $\mathrm{CO}_{2}$ sinks. Nat. Clim. Change 8, 914-920 (2018).

\section{Competing interests}

The author declares no competing interests.

\section{Additional information}

Correspondence and requests for materials should be addressed to S.M.S.

Reprints and permission information is available at http://www.nature.com/reprints

Publisher's note Springer Nature remains neutral with regard to jurisdictional claims in published maps and institutional affiliations. (c) (i) Open Access This article is licensed under a Creative Commons Attribution 4.0 International License, which permits use, sharing, adaptation, distribution and reproduction in any medium or format, as long as you give appropriate credit to the original author(s) and the source, provide a link to the Creative Commons license, and indicate if changes were made. The images or other third party material in this article are included in the article's Creative Commons license, unless indicated otherwise in a credit line to the material. If material is not included in the article's Creative Commons license and your intended use is not permitted by statutory regulation or exceeds the permitted use, you will need to obtain permission directly from the copyright holder. To view a copy of this license, visit http://creativecommons.org/ licenses/by/4.0/.

(C) The Author(s) 2021, corrected publication 2021 